\title{
Correspondence
}

\section{Effects of Ramadan fasting on the symptoms of chronic heart failure}

\section{To the Editor}

We have read with great interest the published article in the Saudi Medical Journal by Abazaid et al, and I congratulate the authors on their work. ${ }^{1}$ This prospective observational study examined the effect of Ramadan fasting on symptoms of patients with chronic heart failure and reduced ejection fraction (less than 40\%). The researchers assessed adherence to fluid and salt restrictions, medication use, and symptoms before, during, and after Ramadan. Ninety-two percent had no changes or improved symptoms, while symptoms worsened in $8 \%$ of patients only. Hospitalization and emergency department visits were more frequent in patients with worsening symptoms compared to those with stable or improved symptoms (39\% versus $0 \%, p \leq 0.0001$ and $50 \%$ versus $10 \%, p \leq 0.0001$, respectively). The study found that patients with worsening symptoms were less likely to have adhered to fluid and salt restrictions (39\% versus 79\%, $p<0.0001$ ) and were less adherent to heart failure drugs ( $67 \%$ versus $94 \%, p<0.0001)$ than those with stable or improved symptoms. These results are reassuring for most of the physicians who are dealing with heart failure patients enquiring on the outcome of fasting. The authors have addressed clearly the limitation of their study and its implementation in regards to diversity in climatic conditions and duration of fasting. The results of this study go in line with others which demonstrated that Ramadan fasting has a positive effect on cardiovascular risk factors.

Finally, I believe that we need more studies that shedding light on such a vital area which is commonly encountered in the clinical practice.

$$
\begin{array}{r}
\text { Abmed Al Fagih } \\
\text { Prince Sultan Cardiac Center } \\
\text { Riyadh, Kingdom of Saudi Arabia }
\end{array}
$$

\section{Reply from the Author}

We are humbled by Dr. Al Fagih gesture expressing his views on our article, and we really appreciate his congratulation note. Comments like this make the work so worthwhile. We concur with his remark that more studies addressing the effects of fasting on different systems are extremely warranted.

Rami Abazid

Prince Sultan Cardiac Center Qassim, Kingdom of Saudi Arabia

\section{References}

1. Abazid RM, Khalaf HH, Sakr HI, Altorbak NA, Alenzi HS, Awad ZM, et al. Effects of Ramadan fasting on the symptoms of chronic heart failure. Saudi Med J 2018; 39: 395-400.

2. Kul S, Savas E, Öztürk ZA, Karadag G. Does Ramadan fasting alter body weight and blood lipids and fasting blood glucose in a healthy population? A meta-analysis. J Relig Health 2014; 53 : 929-942. 